\title{
Discovery and the Disciplines: An Inquiry into the Role of Subject Databases through Citation Analysis
}

\section{Alexa L. Pearce}

Libraries have adopted web scale discovery services with the goal of providing their users with a streamlined research experience. However, the single search box that characterizes web scale discovery is one option among many that libraries continue to provide, including subject databases and other legacy tools. Libraries lack evidence regarding which of these tools are best suited to the various stages and levels of expertise that may characterize a user's research process. A case study approach, focusing on the field of academic history, is employed to test the discoverability of a subset of scholarly work across several search platforms.

\section{Introduction}

The widespread adoption of web scale discovery services by academic research libraries has been accompanied by a general consensus that these tools are poised to meet user expectations for a streamlined research experience. ${ }^{1}$ A Google-like single search box is one of the defining features of web scale discovery tools, promising access to content from disparate source databases via a preharvested central index. ${ }^{2}$ However, in many cases, this single search box continues to serve as one option among many that libraries provide. The full assortment of search interfaces that libraries continue to offer, including catalogs as well as subject-specific databases, comprises a complex discovery ecosystem with myriad options for where and how users may begin and proceed with their research process.

Despite this enduring complexity, libraries lack evidence about which tools are best suited to the various stages and levels of expertise that may characterize a user's discovery experience. The literature is at best anecdotal on this topic, tending to convey an assumption that web scale tools are well suited for novice users and uses while subject-specific databases can best serve more advanced discovery needs. ${ }^{3}$ Moreover, while libraries have produced a wealth of research to understand and evaluate web scale discovery tools in recent years, they have dedicated comparatively little evaluative attention to subject-specific databases, many of which are also known as abstracting and indexing (A\&I) services. ${ }^{4}$ Accordingly, while there is an accumulation of research on topics ranging from the configuration of web scale tools to their usability, there is a comparative lack of evidence with which libraries may discern and

\footnotetext{
*Alexa L. Pearce is Head, Social Sciences \& Clark Library, at the University of Michigan Library; email: alexap@ umich.edu. (C2019 Alexa L. Pearce, Attribution-NonCommercial (http://creativecommons.org/licenses/by-nc/4.0/) CC BY-NC.
} 
describe the continuing value of A\&I tools and other legacy databases, in light of web scale adoption.

This investigation employs a case study approach, focusing on the field of academic history, to test the assumption that subject databases continue to serve advanced discovery needs better than web scale tools. First, the study engages citation analysis to characterize a sample of published historical scholarship by format, publication date, and language. The discoverability of historical literature is then tested across six search platforms, including library-provided tools such as ProQuest's Summon, OCLC's WorldCat, and Historical Abstracts, as well as Google Scholar, which is available freely on the web. Results indicate that historical literature may be more effectively represented by web scale and web-based tools, such as Google Scholar and Summon, than by narrower, subject-specific databases.

\section{Literature Review}

The literature on web scale discovery demonstrates a consensus that users prefer web scale discovery tools when given a choice and that they expect and are comfortable with a search environment characterized by web scale features, such as a single search box, rapid retrieval of results, facets for refinement, and relevance ranking. ${ }^{5}$ The literature also reveals established knowledge of the mechanics and configuration options of web scale discovery services, with many studies emphasizing the primacy of a centralized index. ${ }^{6}$ Yet many aspects of web scale discovery tools remain opaque to library professionals, reflecting the highly competitive commercial environment from which they emerged. For example, while the literature reveals widespread understanding of the centrality and significance of search algorithms, their proprietary nature often precludes deeper understanding of how specific discovery services find, rank, and display results. Additionally, library professionals continue to grapple with discerning exactly which content is included by discovery tools in both search and display modes.7

While librarian attitudes are documented less prominently than user attitudes in the literature, there is evidence to suggest that the lack of transparency around web scale discovery services contributes to enduring reservations among librarians, regarding their efficacy. Indeed, NISO's Open Discovery Initiative (ODI) was formed to advocate for and facilitate the disclosure of details related to the exposure of metadata, content, and indexing among the full community of discovery stakeholders. ${ }^{8}$ While the ODI has made some progress toward modeling better disclosure practices, web scale discovery tools are still perceived as moving targets, in terms of tracking what they do and do not index. By comparison, A\&I databases have traditionally offered relatively stable title lists and, as a result, may more readily earn the confidence of some library professionals. ${ }^{9}$

Library professionals have identified beneficial outcomes for the adoption of web scale discovery services, in spite of their opacity. For example, instruction librarians have noted that teaching a single interface, instead of several, affords time in the classroom to focus on higher-level concepts and techniques. ${ }^{10}$ Additionally, the literature demonstrates an emerging sense that web scale services play a worthwhile role in the research process, though this role is commonly described as complementary or supplementary, suggesting that web scale tools may coexist with, but not replace, subject-specific databases. ${ }^{11}$

However, the nature of the complementary relationship remains somewhat vague. The literature reflects an anecdotal view that web scale tools are appropriate for novice users or as starting points, while subject databases can better serve advanced users and uses. ${ }^{12}$ This as- 
sertion has yet to be tested through any specific disciplinary lens or with attention to indexed content. Moreover, there is some evidence to support an opposing view. In their discussion of learning to teach the web scale discovery service called Summon, Catherine Cardwell, Vera Lux, and Robert J. Snyder found that it is "not the most efficient starting point in all circumstances" and noted positive impressions of Summon among faculty and graduate students, supporting a conclusion that it "can be much more than a simple tool for novice users."13

The few comparative studies that have included subject databases or A\&I tools have not necessarily applied equal scrutiny across all tools or have produced mixed results. For example, Andrew D. Asher, Lynda M. Duke, and Suzanne Wilson found that the EBSCO Discovery Service (EDS) outperformed ProQuest's Summon, Google Scholar, and conventional library catalogs and databases in an investigation of undergraduates' research habits and their ability to find relevant results based on preformulated questions. ${ }^{14}$ However, this study did not name the conventional databases that students consulted, nor did it separate them from library catalogs for the purposes of comparison. In a rigorous comparison of student searching between Summon and the A\&I service called Social Sciences Abstracts, Sarah P.C. Dahlen and Kathlene Hanson found that students expressed preference for and reported greater ease of use with Summon. ${ }^{15}$ Articles selected by students through test searches of both tools were also evaluated by librarians, who found that authority, as defined by the taxonomy developed by Chris Leeder, Karen Markey, and Elizabeth Yakel, was higher for articles retrieved from Social Sciences Abstracts than for articles retrieved from Summon, while relevance was higher for articles retrieved from Summon. ${ }^{16}$ Dahlen and Hanson concluded that discovery layers and subject-specific databases have complementary strengths and that both continue to serve a purpose in the larger context of library resources. Dahlen and Hanson also reiterated the prevailing view that subject-specific databases may be better suited for advanced disciplinary uses than discovery services, though they acknowledged the potential utility for discovery tools in "conducting searches on esoteric topics."17

In seeking to better understand the relationship between subject databases and web scale tools, the present study acknowledges methodological challenges. Many standard methods that the profession has relied upon for database evaluation date to the 1980s or early 1990s, if not earlier, and were not developed to account for the range of variables that affect the efficacy of web scale discovery tools, from local configuration and access restrictions to dynamic content representation. ${ }^{18}$ Nor have existing methods been tested against the growing scale of information resources that characterizes the twenty-first century library discovery environment. ${ }^{19}$ Accordingly, this study shifts its focus away from database evaluation as such, seeking instead to understand the nature of scholarly literature in a specific subject area, academic history, as a prerequisite for testing the discoverability of this literature across platforms.

Regarding history specifically, several studies that analyze information needs and information-seeking behaviors of academic historians date to the 1970s and 1980s, and many have focused on specified subfields and formats, such as Kee DeBoer's study on journal literature in U.S. history. ${ }^{20}$ More recent studies that analyze useful platforms for finding historical literature have also tended to analyze lists of journal titles indexed, to the exclusion of monographs and other formats. ${ }^{21}$ The emphasis on journal literature does not align with findings from previous investigations. For example, Clyve Jones, Michael Chapman, and Pamela Carr Woods found that historians used nonserial sources, "especially monographs," to a far greater degree than serial sources, while Margaret F. Stieg found that historians described books as the most convenient source types, compared to others, and were unlikely to consult indexes or abstracts, 
which many viewed as "irrelevant." ${ }^{22}$ While both of those studies are several decades old, their findings on historians' preferences for books have yet to be contradicted in the literature or elsewhere. For example, Margaret Stieg Dalton and Laurie Charnigo's 2004 sequel to Stieg's study found that journal articles and book chapters had increased in significance to historians, but books remained dominant. ${ }^{23} \mathrm{M}$. Sara Lowe found that nonserial use exceeded serial use at a fairly consistent rate over several decades, with nonserial use at 71.4 percent in $2002 .{ }^{24}$ Despite these findings, the emphasis on journal literature has persisted in evaluative studies. In their relatively recent comparison of Historical Abstracts to Google Scholar, Hal P. Kirkwood and Monica C. Kirkwood noted that they found more book results in Google Scholar than in Historical Abstracts..$^{25}$ The authors remarked that this was "not intrinsically bad," but they did not admit the possibility that the inclusion of book results could be beneficial to academic historians and concluded, not for that reason alone, that Historical Abstracts was the superior tool. ${ }^{26}$

This study presents an updated investigation of the characteristics of historical literature to better inform the question of where it may be found. By testing an inclusive discovery environment for historical scholarship, the present study adds clarity to questions about the relative strengths and weaknesses of coexisting search platforms and their optimal roles and placement in a user's process.

\section{Methodology}

This study's citation analysis drew upon all secondary literature cited in the American Historical Review (AHR) during a six-year period, from 2010 through 2015. The $A H R$ is the official publication of the American Historical Association (AHA) and, as stated on its website, has served as "the journal of record for the historical profession in the United States since 1895." ${ }^{27}$ While the scholarly conversation in history extends beyond the $A H R$, its flagship status situates it well to represent current and prominent research and debates in the field. Additionally, the AHR represents all subfields of history in its research articles and reviews of new scholarship. For this study, the author gathered citations from research articles only. While reviews facilitate discovery of new scholarship for many historians, they were excluded from this study because they do not tend to cite sources in the extensive manner of research articles.

$A H R$ research articles tend to cite a combination of scholarly secondary works, such as books, journal articles, chapters, and dissertations, along with extensive archival sources and other primary materials. For the purposes of testing the library discovery environment and creating a fair basis for comparison, the author included citations to published and secondary materials and excluded citations to archival and manuscript sources. The rationale for this decision was to develop a sample of citations that a researcher could reasonably expect to find using library search tools, as opposed to archival finding aids. Research libraries do offer specialized tools and expertise for locating archival and manuscript sources, but these functions have traditionally remained outside the indexing scope of history subject databases, such as Historical Abstracts.

The process for gathering citations entailed reading through all endnotes attached to the research articles included in the study. Citations that met criteria for inclusion were copied and pasted by hand into a spreadsheet. In addition to excluding archival and manuscript sources, as described above, the author excluded citations to newspaper and popular press articles published prior to 1900. Citations to entire periodicals, as opposed to articles, were also excluded. Books from all date ranges were included. Citations to nonscholarly newspaper and magazine articles published after 1900 were included. Citations to published primary sources were also included. 
These criteria were designed to focus the study on secondary literature as much as possible and to mitigate inherent advantages that some of the included search platforms may have. For example, general and popular press articles published prior to the twentieth century are somewhat likely to be used as primary sources by historians and are not within the scope of indexing for Historical Abstracts or America: History and Life but may be cataloged, by chance, in WorldCat.

The resulting population comprised 22,572 citations. After separating duplicates, the total number was 19,937 . Using a random number generator, the deduplicated list was reordered to allow selection of a random sample of 400 citations, which affords a confidence level of 95 percent and a confidence interval of 5 . All further discussion relates to testing and analysis of the sample, but the entire citation population, including the deduplicated list, is available for consultation and reuse via the author's institutional repository for research data. ${ }^{28}$

The first step in analysis was to characterize each citation according to format, publication date, and language. Book introductions were recognized and coded as formats if the citation included a named author or title, in the manner of a book chapter. If an introduction was cited without author or title information, the citation was treated as a whole book. The published data for this study includes precise publication dates for each citation. However, for the purposes of analysis, dates were grouped and coded by decade, starting from the year 01 and ending in 10. The 1990s, for example, includes all citations published between 1991 and 2000. Tables 1-3 present all formats, date ranges, and languages present in the sample of citations. Second, the author searched for all citations in 6 different search platforms, namely:

- Historical Abstracts

- America: History and Life

- JSTOR

- Google Scholar

- WorldCat

- ArticlesPlus (Summon)

The primary question for each database included in the study was how comprehensively it represented the sample of $A H R$ citations. For a citation to count as present in a database, it had to be represented in the format in which it was cited. For example, if a search for a book turned up a dissertation with the same author and very similar title, the citation was not considered present. Similarly, if a search for a book chapter turned up a result for the same essay published elsewhere as a journal article, the citation was not counted as present. It was not necessary for book chapters to have their own records, but it was necessary for them to be discernible among search results as chapters, such as in a table of contents listing.

To expedite the search process, Historical Abstracts and America: History and Life were searched simultaneously. For all of the platforms except Google Scholar, advanced searches were performed, with both title and author information entered for each citation. All searching took place between February and May of 2017. The results presented here reflect the content available at the time of investigation. Because the intent of this study is to understand discovery broadly, rather than through the lens of a single institution's configurations, the author selected the options to search across all content in both JSTOR and Summon, rather than limiting to content that is available only to the affiliated institution, the University of Michigan (U-M) Library. The other tools included do not discriminate between a full body of indexed literature and a subset of that literature that is available for institutional access. Following are additional details about why each tool was selected for inclusion. 


\section{America: History and Life and Historical Abstracts}

America: History and Life and Historical Abstracts (AHL/HA) were selected for inclusion as the two databases that the academic library profession recognizes as primary indexes to published scholarship in history. Both are available exclusively on the EBSCO platform. The U-M Library subscribes to the full-text versions of each, though access to full text was not a consideration for this study. Historical Abstracts indexes scholarship on all aspects of world history, excluding the U.S. and Canada, from 1450 to the present. America: History and Life covers all time periods in U.S. and Canadian history. Both are known for offering a unique option to limit searches by time period of interest. Recognizing the two indexes as "companion and complementary services" and providing combined analysis follows the convention used previously by DeBoer. ${ }^{29}$

\section{JSTOR}

JSTOR was selected based on its widespread name recognition among historians, history students, and other scholars working on historical topics. ${ }^{30}$ While library professionals are aware that JSTOR does not serve as a formal indexing tool, owing to its lack of descriptive metadata, library users do not generally make this distinction. While some library users may consult JSTOR with awareness of its role as a digital archive, many users also think of it as a place to identify current and relevant scholarship of interest, across subject areas.

\section{Google Scholar}

Google Scholar was selected based on its continuing prominence among the web-based search engines that many scholars and students consult frequently. Though library professionals continue to debate its merits, Google Scholar searches a vast universe of content without explicit disciplinary or format-based boundaries around what it includes and excludes. As the original tool that succeeded in bringing the Google search experience, characterized by speed and relevance, to the world of academic scholarship, it has a useful presence in any study that seeks to measure legacy tools against newly dominant search interfaces.

\section{WorldCat}

WorldCat was selected based on its continuing ability to function as and represent a research library catalog, as opposed to a disciplinary index or discovery service. WorldCat includes records for a plethora of formats in addition to books. Given the breadth and depth of WorldCat's holdings, the author believed it would add a dimension to the study that no other tool could replicate and would thereby provide an interesting point of comparison to both disciplinary tools and discovery services. This study consulted WorldCat via the FirstSearch interface, as opposed to using WorldCat.org, WorldCat Local, or WorldCat Discovery.

\section{ArticlesPlus (Summon)}

ArticlesPlus is the U-M Library's locally branded configuration of ProQuest's Summon discovery service. U-M built the front end using the vendor's API, but the content is otherwise the same as using the native interface. The U-M Library has not chosen to include its catalog holdings in ArticlesPlus. ${ }^{31}$ It is the only web scale discovery service in the study, as defined by its centralized index of academic, news, reference, and popular content sourced from various publishers, content providers, and subject areas. While it cannot represent the strengths and 
weaknesses of all commercial discovery services, the author believes there is value in comparing its coverage of the $A H R$ sample to the coverage afforded by the other tools. Further research that includes one of Summon's main competitors would also be of value.

\section{Results}

\section{Part 1: Characterizing the Sample}

The sample of 400 citations was found to include English language materials, predominantly, with 333 citations in English, accounting for 83.25 percent of the sample. The next largest language representations were French, with 31 citations (7.75\%), and German, with 11 citations (3\%). Table 1 presents the language breakdown of the sample.

\begin{tabular}{|l|c|c|}
\hline \multicolumn{3}{|c|}{ TABLE 1 } \\
Sample Broken Down by Language \\
(N = 400) \\
\hline English & 333 & $83.25 \%$ \\
\hline French & 31 & $7.75 \%$ \\
\hline German & 11 & $3.00 \%$ \\
\hline Spanish & 7 & $1.75 \%$ \\
\hline Russian & 5 & $1.00 \%$ \\
\hline Italian & 3 & $0.75 \%$ \\
\hline Japanese & 3 & $0.75 \%$ \\
\hline Hebrew & 2 & $0.50 \%$ \\
\hline Arabic & 1 & $0.25 \%$ \\
\hline Breton & 1 & $0.25 \%$ \\
\hline Croatian & 1 & $0.25 \%$ \\
\hline Ladino & 1 & $0.25 \%$ \\
\hline Latin & 1 & $0.25 \%$ \\
\hline
\end{tabular}

\begin{tabular}{|l|c|c|}
\hline \multicolumn{3}{|c|}{ TABLE 2} \\
Sample Broken Down by Format (N = 400) \\
\hline Monograph & 196 & $49.0 \%$ \\
\hline Journal article & 90 & $22.5 \%$ \\
\hline Book chapter & 41 & $10.25 \%$ \\
\hline Edited volume & 24 & $6.00 \%$ \\
\hline Published primary source & 14 & $3.50 \%$ \\
\hline Newspaper article & 12 & $3.00 \%$ \\
\hline Series & 8 & $2.00 \%$ \\
\hline Book introduction & 5 & $1.00 \%$ \\
\hline Conference proceedings & 2 & $0.50 \%$ \\
\hline Film & 2 & $0.50 \%$ \\
\hline Web article & 2 & $0.50 \%$ \\
\hline Digital scholarship & 1 & $0.25 \%$ \\
\hline Grey literature & 1 & $0.25 \%$ \\
\hline Magazine article & 1 & $0.25 \%$ \\
\hline Photograph & 1 & $0.25 \%$ \\
\hline
\end{tabular}

Excluding the 11 citations that were translated into English, there were 322 English language citations. Of these, 150 (47\%) were monographs.

Broken down by format, close to half of the sample consisted of citations to monographs. There were 196 monograph citations, accounting for 49 percent. Academic journal articles formed the second largest subset, with 90 citations $(22.5 \%)$. Book chapters were the third largest subset, with 41 citations (10.25\%). Table 2 presents the format breakdown of the sample.

Of the 196 monographs in the sample, 150 (77\%) were English language, not including translations into English.

Broken down by date range of publication, no subset emerged with as large a share of the sample as in the other two categories. The largest subset included citations published during the first decade of the twenty-first century, 2001-2010, with 141 citations (35.25\%). The next largest subset was the 1990s, with 61 citations (15.25\%), followed by the 1980s with 45 citations $(11.25 \%)$. Table 3 presents the date range breakdown of the sample. 


\begin{tabular}{|c|c|c|}
\hline \multicolumn{3}{|c|}{$\begin{array}{c}\text { TABLE } 3 \\
\text { Sample Broken Down by Date } \\
\text { Range of Publication ( } N=400 \text { ) }\end{array}$} \\
\hline $2000 s$ & 141 & $35.25 \%$ \\
\hline 1990s & 61 & $15.25 \%$ \\
\hline $1980 \mathrm{~s}$ & 45 & $11.25 \%$ \\
\hline 2010s & 39 & $9.75 \%$ \\
\hline $1960 \mathrm{~s}$ & 27 & $6.75 \%$ \\
\hline $1970 \mathrm{~s}$ & 23 & $5.75 \%$ \\
\hline 1950s & 14 & $3.50 \%$ \\
\hline 19th century & 11 & $2.75 \%$ \\
\hline 1920s & 10 & $2.50 \%$ \\
\hline $1930 s$ & 8 & $2.00 \%$ \\
\hline 1940s & 8 & $2.00 \%$ \\
\hline Pre-1801 & 6 & $1.50 \%$ \\
\hline 1910s & 4 & $1.00 \%$ \\
\hline $1900 \mathrm{~s}$ & 3 & $0.75 \%$ \\
\hline
\end{tabular}

\section{Part 2: Finding the Sample}

Google Scholar emerged as the search platform where most citations in the sample could be found. Of the 400 citations, 335 (83.75\%) were represented in Google Scholar. ArticlesPlus followed closely, with records for 318 citations $(79.5 \%)$. WorldCat held records for the third highest portion of the sample, with 272 (68\%). Both JSTOR and AHL/HA represented far fewer citations than the other three. Table 4 presents the number of citations found in each platform.

\begin{tabular}{|l|c|c|}
\hline \multicolumn{3}{|c|}{ TABLE 4 } \\
Number of Citations Represented in Each Search \\
Platform (N=400)
\end{tabular}

Results were further broken down to see how well each tool approximated the sample in terms of date range, language, and publication. Each search tool found a majority of English language citations. Google Scholar, ArticlesPlus, and WorldCat came closest to matching the sample's English percentage of 83.25 percent. Of the 335 citations found in Google Scholar, 296 (88.36\%) were in English. In ArticlesPlus, 278 (87.42\%) of the 318 citations were in English. Of WorldCat's 272 citations, 227 (83.46\%) were in English. The AHL/HA citations were 95.25 percent English, or 80 out of a total of 84 . For JSTOR, the figure was even higher, at 96.96 percent, or 64 out of 66.

The set of citations found in WorldCat included nine languages, out of thirteen included in the full sample. ArticlesPlus included eight of thirteen languages, while Google Scholar included seven. AHL/HA included four languages, while JSTOR included only two: English and French.

Table 5 provides a language breakdown comparison across the full sample and the subsets of citations that were found in each platform.

Broken down by format, Google Scholar and ArticlesPlus came closest to mirroring the sample by finding more monographs than any other format. The Google Scholar subset included 175 monographs (52.24\%), a slightly higher rate than the 49 percent found in the full sample. In ArticlesPlus, monographs accounted for 180 citations (56.6\%). In both the JSTOR and AHL/HA subsets, there were more journal articles than monographs. In AHL/HA, there were 36 monographs out of 84 total citations (42.86\%), while JSTOR contained 28 monograph citations out of 66 total $(42.42 \%)$. The AHL/HA subset included 39 journal article citations $(46.43 \%)$, which is more than double the proportion in the full sample, which was 22.5 percent. JSTOR's subset included 34 journal article citations (51.51\%), which also more than doubled the portion represented in the sample. 


\begin{tabular}{|c|c|c|c|c|c|c|}
\hline \multicolumn{7}{|c|}{$\begin{array}{c}\text { TABLE } 5 \\
\text { Language Breakdown Compared Across Platforms }\end{array}$} \\
\hline Language & $\begin{array}{c}\text { Percent } \\
\text { of } \\
\text { Sample } \\
(\mathrm{N}=400)\end{array}$ & $\begin{array}{c}\begin{array}{c}\text { Percent } \\
\text { of Google } \\
\text { Scholar subset } \\
(n=335)\end{array} \\
\end{array}$ & $\begin{array}{c}\begin{array}{c}\text { Percent of } \\
\text { ArticlesPlus } \\
\text { subset } \\
(\mathbf{n}=\mathbf{3 1 8})\end{array} \\
\end{array}$ & $\begin{array}{c}\text { Percent of } \\
\text { WorldCat } \\
\text { subset } \\
(\mathbf{n}=\mathbf{2 7 2})\end{array}$ & $\begin{array}{c}\text { Percent } \\
\text { of AHL/ } \\
\text { HA subset } \\
(\mathbf{n}=\mathbf{8 4})\end{array}$ & $\begin{array}{c}\begin{array}{c}\text { Percent } \\
\text { of JSTOR } \\
\text { subset } \\
(n=66)\end{array} \\
\end{array}$ \\
\hline English & $83.25 \%$ & $88.36 \%$ & $87.42 \%$ & $83.46 \%$ & $95.23 \%$ & $96.96 \%$ \\
\hline French & $7.75 \%$ & $6.27 \%$ & $7.55 \%$ & $9.56 \%$ & $2.38 \%$ & $3.03 \%$ \\
\hline German & $3.00 \%$ & $2.09 \%$ & $2.20 \%$ & $1.84 \%$ & & \\
\hline Spanish & $1.75 \%$ & $1.79 \%$ & $1.26 \%$ & $2.21 \%$ & & \\
\hline Russian & $1.00 \%$ & $0.30 \%$ & $0.31 \%$ & $0.37 \%$ & $1.19 \%$ & \\
\hline Italian & $0.75 \%$ & $0.90 \%$ & $0.63 \%$ & $1.10 \%$ & $1.19 \%$ & \\
\hline Japanese & $0.75 \%$ & $0.30 \%$ & $0.31 \%$ & $0.74 \%$ & & \\
\hline Hebrew & $0.50 \%$ & & & & & \\
\hline Arabic & $0.25 \%$ & & & & & \\
\hline Breton & $0.25 \%$ & & $0.31 \%$ & $0.37 \%$ & & \\
\hline Croatian & $0.25 \%$ & & & & & \\
\hline Ladino & $0.25 \%$ & & & & & \\
\hline Latin & $0.25 \%$ & & & $0.37 \%$ & & \\
\hline
\end{tabular}

The set of citations found in Google Scholar included 11 formats, of 15 total in the sample. Both WorldCat and ArticlesPlus included 10 of these 15 formats. AHL/HA included six formats, while JSTOR included just four.

Table 6 provides a format breakdown comparison across the full sample and the subsets of citations that were found in each search platform.

Google Scholar, ArticlesPlus, and WorldCat came closest to mirroring the sample in terms of its date range breakdown. In the sample, the largest date range subset was the 2000s, with 141 out of 400 citations (35.25\%). This decade was represented by 127 citations in Google Scholar's subset of 335 (37.91\%). In ArticlesPlus, the 2000s were represented by 119 citations out of $318(37.42 \%)$. In WorldCat, 93 citations were from the 2000s, out of 272 (34.19\%). In AHL/HA, the portion was higher than the sample with 41 out of 84 citations from the 2000s $(48.81 \%)$, while 31 out of $66(46.97 \%)$ of the JSTOR sample was from this date range.

The full sample included 14 date range categories, all of which were represented in the Google Scholar, WorldCat, and ArticlesPlus subsets. AHL/HA included seven date range categories, with no citations dated prior to the 1950s. JSTOR included eight date range categories, with no citations dated prior to the 1920s.

Table 7 provides a date range breakdown comparison across the full sample and the subsets of citations that were found in each search platform.

In the sample of 400 citations, there were $38(9.5 \%)$ that were uniquely represented in only one of the search platforms consulted. ${ }^{32}$ Of these, 18 (47.37\%) were found in Google Scholar. Ten of the uniquely represented citations $(26.32 \%)$ were in WorldCat, while eight $(21.05 \%)$ were in ArticlesPlus. AHL/HA indexed one of the uniquely represented citations (2.63\%), and JSTOR did not include any citations that were not also represented in another platform. The unique citations in Google Scholar were mostly English language book chapters. Similarly, a small plurality of the unique citations in WorldCat were English language book chapters. In 


\begin{tabular}{|c|c|c|c|c|c|c|}
\hline \multicolumn{7}{|c|}{$\begin{array}{c}\text { TABLE } 6 \\
\text { Format Breakdown Compared Across Platforms }\end{array}$} \\
\hline Format & $\begin{array}{c}\text { Percent } \\
\text { of Sample } \\
(\mathrm{N}=400)\end{array}$ & $\begin{array}{c}\begin{array}{c}\text { Percent } \\
\text { of Google } \\
\text { Scholar subset } \\
(n=335)\end{array} \\
\end{array}$ & $\begin{array}{c}\text { Percent of } \\
\text { ArticlesPlus } \\
\text { subset } \\
(n=318)\end{array}$ & $\begin{array}{l}\text { Percent of } \\
\text { WorldCat } \\
\text { subset } \\
(n=272)\end{array}$ & $\begin{array}{c}\text { Percent } \\
\text { of AHL/ } \\
\text { HA subset } \\
(n=84)\end{array}$ & $\begin{array}{c}\text { Percent } \\
\text { of JSTOR } \\
\text { subset } \\
(n=66)\end{array}$ \\
\hline Monograph & $49.0 \%$ & $52.24 \%$ & $56.6 \%$ & $69.85 \%$ & $42.86 \%$ & $42.42 \%$ \\
\hline Journal article & $22.5 \%$ & $24.78 \%$ & $25.79 \%$ & $6.62 \%$ & $46.43 \%$ & $51.51 \%$ \\
\hline Book chapter & $10.25 \%$ & $8.96 \%$ & $5.03 \%$ & $6.99 \%$ & $1.19 \%$ & $3.03 \%$ \\
\hline Edited volume & $6.00 \%$ & $7.16 \%$ & $6.29 \%$ & $8.82 \%$ & $7.14 \%$ & $3.03 \%$ \\
\hline $\begin{array}{l}\text { Published primary } \\
\text { source }\end{array}$ & $3.50 \%$ & $2.39 \%$ & $1.89 \%$ & $2.94 \%$ & $1.19 \%$ & \\
\hline Newspaper article & $3.00 \%$ & $0.30 \%$ & $1.26 \%$ & & & \\
\hline Series & $2.00 \%$ & $1.79 \%$ & $2.20 \%$ & $2.94 \%$ & $1.19 \%$ & \\
\hline Book introduction & $1.00 \%$ & $1.19 \%$ & $0.31 \%$ & & & \\
\hline $\begin{array}{l}\text { Conference } \\
\text { proceedings }\end{array}$ & $0.50 \%$ & & & $0.37 \%$ & & \\
\hline Film & $0.50 \%$ & & $0.31 \%$ & $0.74 \%$ & & \\
\hline Web article & $0.50 \%$ & $0.6 \%$ & & & & \\
\hline Digital scholarship & $0.25 \%$ & $0.30 \%$ & & $0.37 \%$ & & \\
\hline Grey literature & $0.25 \%$ & $0.30 \%$ & & $0.37 \%$ & & \\
\hline Magazine article & $0.25 \%$ & & $0.31 \%$ & & & \\
\hline Photograph & $0.25 \%$ & & & & & \\
\hline
\end{tabular}

TABLE 7

Publication Date Range Breakdown Compared Across Search Platforms

\begin{tabular}{|l|c|c|c|c|c|c|}
\hline Date Range & $\begin{array}{c}\text { Percent } \\
\text { of Sample } \\
\mathbf{( N = 4 0 0 )}\end{array}$ & $\begin{array}{c}\text { Percent of } \\
\text { Google Scholar } \\
\text { subset (n=335) }\end{array}$ & $\begin{array}{c}\text { Percent of } \\
\text { ArticlesPlus } \\
\text { subset } \\
\text { (n=318) }\end{array}$ & $\begin{array}{c}\text { Percent of } \\
\text { WorldCat } \\
\text { subset } \\
\text { (n=272) }\end{array}$ & $\begin{array}{c}\text { Percent } \\
\text { of AHL/ } \\
\text { HA subset } \\
\text { (n=84) }\end{array}$ & $\begin{array}{c}\text { Percent } \\
\text { of JSTOR } \\
\text { subset } \\
\text { (n=66) }\end{array}$ \\
\hline $2000 \mathrm{~s}$ & $35.25 \%$ & $37.91 \%$ & $37.42 \%$ & $34.19 \%$ & $48.81 \%$ & $46.97 \%$ \\
\hline $1990 \mathrm{~s}$ & $15.25 \%$ & $16.42 \%$ & $15.09 \%$ & $17.65 \%$ & $15.48 \%$ & $15.15 \%$ \\
\hline $1980 \mathrm{~s}$ & $11.25 \%$ & $11.94 \%$ & $11.64 \%$ & $12.5 \%$ & $21.42 \%$ & $13.64 \%$ \\
\hline $2010 \mathrm{~s}$ & $9.75 \%$ & $9.55 \%$ & $9.43 \%$ & $6.99 \%$ & $5.95 \%$ & $12.12 \%$ \\
\hline $1960 \mathrm{~s}$ & $6.75 \%$ & $6.57 \%$ & $6.60 \%$ & $6.99 \%$ & $3.57 \%$ & $6.06 \%$ \\
\hline $1970 \mathrm{~s}$ & $5.75 \%$ & $5.97 \%$ & $5.97 \%$ & $5.88 \%$ & $3.57 \%$ & $3.03 \%$ \\
\hline $1950 \mathrm{~s}$ & $3.50 \%$ & $2.09 \%$ & $3.46 \%$ & $3.31 \%$ & $1.19 \%$ & \\
\hline $19 \mathrm{th}$ century & $2.75 \%$ & $2.09 \%$ & $1.89 \%$ & $2.57 \%$ & & \\
\hline $1920 \mathrm{~s}$ & $2.50 \%$ & $1.49 \%$ & $1.26 \%$ & $1.47 \%$ & & $1.52 \%$ \\
\hline $1930 \mathrm{~s}$ & $2.00 \%$ & $1.49 \%$ & $2.20 \%$ & $2.21 \%$ & & \\
\hline $1940 \mathrm{~s}$ & $2.00 \%$ & $2.09 \%$ & $2.52 \%$ & $2.57 \%$ & & $1.52 \%$ \\
\hline Pre-1801 & $1.50 \%$ & $0.90 \%$ & $1.26 \%$ & $2.21 \%$ & & \\
\hline $1910 \mathrm{~s}$ & $1.00 \%$ & $0.90 \%$ & $0.94 \%$ & $0.74 \%$ & & \\
\hline $1900 \mathrm{~s}$ & $0.75 \%$ & $0.60 \%$ & $0.31 \%$ & $0.74 \%$ & & \\
\hline
\end{tabular}


ArticlesPlus, the majority of unique citations were English language newspaper and magazine articles. Tables 8-11 present characteristics of the 38 citations that were uniquely represented in one of the six search platforms.

\section{TABLE 8}

Characteristics of Citations Found Only in Google Scholar $(n=18)$

\begin{tabular}{|l|c|c|c|c|c|}
\hline Language & Number & Format & Number & Date Range & Number \\
\hline English & 15 & Book Chapter & 9 & $2000 \mathrm{~s}$ & 5 \\
\hline French & 1 & Monograph & 2 & $2010 \mathrm{~s}$ & 3 \\
\hline Russian & 1 & Journal article & 2 & $1990 \mathrm{~s}$ & 3 \\
\hline Japanese & 1 & Web article & 2 & 19 th century & 2 \\
\hline & & Published primary source & 1 & $1960 \mathrm{~s}$ & 1 \\
\hline & & Book introduction & 1 & $1910 \mathrm{~s}$ & 1 \\
\hline & & Newspaper article & 1 & $1920 \mathrm{~s}$ & 1 \\
\hline & & & & $1970 \mathrm{~s}$ & 1 \\
\hline & & & & $1980 \mathrm{~s}$ & 1 \\
\hline
\end{tabular}

TABLE 9

Characteristics of Citations Found Only in WorldCat $(n=10)$

\begin{tabular}{|l|c|c|c|c|c|}
\hline Language & Number & Format & Number & Date Range & Number \\
\hline English & 7 & Monograph & 4 & $1990 \mathrm{~s}$ & 3 \\
\hline French & 1 & Book chapter & 3 & $2000 \mathrm{~s}$ & 2 \\
\hline Japanese & 1 & Conference proceeding & 1 & $1970 \mathrm{~s}$ & 1 \\
\hline Latin & 1 & Film & 1 & $1950 \mathrm{~s}$ & 1 \\
\hline & & Published Primary source & 1 & $1920 \mathrm{~s}$ & 1 \\
\hline & & & & 19 th century & 1 \\
\hline & & & & Pre-1800 & 1 \\
\hline
\end{tabular}

TABLE 10

Characteristics of Citations Found Only in ArticlesPlus (n=8)

\begin{tabular}{|l|c|c|c|c|c|}
\hline Language & Number & Format & Number & Date Range & Number \\
\hline English & 7 & Newspaper article & 4 & $2010 \mathrm{~s}$ & 2 \\
\hline French & 1 & Journal article & 2 & $1950 \mathrm{~s}$ & 2 \\
\hline & & Magazine article & 1 & $2000 \mathrm{~s}$ & 1 \\
\hline & & Book chapter & 1 & $1930 \mathrm{~s}$ & 1 \\
\hline & & & & $1920 \mathrm{~s}$ & 1 \\
\hline & & & & $1910 \mathrm{~s}$ & 1 \\
\hline
\end{tabular}

TABLE 11

Characteristics of Citations Found Only in AHL/HA $(n=1)$

\begin{tabular}{|l|c|c|c|c|c|}
\hline Language & Number & Format & Number & Date Range & Number \\
\hline Russian & 1 & Journal article & 1 & $2000 \mathrm{~s}$ & 1 \\
\hline
\end{tabular}


Thirty citations from the sample $(7.5 \%)$ were not found in any of the search platforms consulted. ${ }^{33}$ The format breakdown was varied, but there were pluralities among book chapters $(23 \%)$ and newspaper articles $(23 \%)$. The date range breakdown among this set was also varied, with a small plurality in the 2000s (17\%). Nine languages were included, out of 13 in the full sample. Fifteen, or half of the citations that were not found, were in English (50\%). Table 12 presents selected characteristics of the 30 citations that were not found.

\begin{tabular}{|l|c|c|c|c|c|}
\hline \multicolumn{7}{|c|}{ TABLE 12} \\
\hline Language & Number & Format & Number & Date Range & Number \\
\hline English & 15 & Book chapter & 7 & $2000 \mathrm{~s}$ & 5 \\
\hline German & 4 & Newspaper article & 7 & $1960 \mathrm{~s}$ & 4 \\
\hline French & 3 & Published Primary Source & 5 & $1980 \mathrm{~s}$ & 4 \\
\hline Hebrew & 2 & Journal article & 4 & $1990 \mathrm{~s}$ & 3 \\
\hline Russian & 2 & Monograph & 4 & $2010 \mathrm{~s}$ & 3 \\
\hline Arabic & 1 & Book Introduction & 1 & $1920 \mathrm{~s}$ & 3 \\
\hline Croatian & 1 & Photograph & 1 & $1950 \mathrm{~s}$ & 2 \\
\hline Ladino & 1 & Conference Proceeding & 1 & 19 th century & 2 \\
\hline Spanish & 1 & & & $1970 \mathrm{~s}$ & 2 \\
\hline & & & & $1930 \mathrm{~s}$ & 1 \\
\hline
\end{tabular}

Eleven citations (2.75\%) were found in all of the search platforms. ${ }^{34}$ These citations were far less varied than those that were not found. All were English language citations, and a majority (7) were monographs. Most were from the 2000s, with a few from the 1980s and 1990s. Table 13 presents selected characteristics of the 11 citations that were found in all platforms.

\begin{tabular}{|l|c|c|c|c|c|}
\hline \multicolumn{7}{|c|}{ TABLE 13 } \\
\hline Language & Number & Format & Number & Date Range & Number \\
\hline English & 11 & Monograph & 7 & $2000 \mathrm{~s}$ & 6 \\
\hline & & Journal article & 3 & $1990 \mathrm{~s}$ & 3 \\
\hline & & Edited volume & 1 & $1980 \mathrm{~s}$ & 2 \\
\hline
\end{tabular}

\section{Discussion}

\section{Part 1: What Do Historians Cite?}

This study suggests that English language monographs maintain unrivaled prevalence among materials that historians are most likely to cite, across subfields of history. Librarians who work closely with humanities-oriented historians are unlikely to be surprised by this finding, as it supports anecdotal understanding of the monograph's enduring significance. This result also aligns with earlier findings, including Dalton and Charnigo's 2004 follow-up to the 1981 Stieg study and Lowe's 2003 analysis, which also drew upon cited references from the $A H R \cdot{ }^{35}$ While history, as a profession, continues to expand and support the use of digital tools and 
methods to produce and evaluate new scholarship, ${ }^{36}$ this study suggests that the monograph persists as the format most likely to be cited in secondary historical literature. Journal articles formed the second-highest share of the sample but accounted for less than a quarter of the 400 citations, while monographs accounted for just about half. Book chapters and edited volumes, both of which are book formats, comprised the next largest format subsets represented in the sample, after journal articles. Nonbook formats aside from journal articles were represented in much smaller numbers.

Considering the publication date ranges represented in the sample, it is worth noting that the dominance of monographs does not necessarily equate to a lack of interest in currency. The sample demonstrated historians' tendency to cite relatively recent work, with the largest plurality of sources aged to the previous decade. Dalton and Charnigo found some evidence to support a perception that "article-length publications," including book chapters, have become more frequently cited by historians than they were at the time of the Stieg study and offered an increased value for currency as one possible explanation. ${ }^{37}$ The present study reinforces that such an interest in currency need not preclude the use and citation of books.

Given the exclusion of archival sources, government information, and manuscript material, it is unsurprising that book formats were so heavily weighted in the sample. The excluded formats were left out to form a fair basis for comparison among discovery and web platforms and conventional disciplinary indexes, as the latter have never specialized in the discovery of archival, government, or manuscript sources. However, the promise of discovery services is to unite disparate and unique formats into a single search experience, prompting a compelling case for further research that takes into account all cited sources.

Further considering the publication date ranges of cited sources, the sample was overwhelmingly recent, though not immediately recent. Unlike the language and format breakdowns, there was not a single date range that represented a majority or approached half of the sample. Instead, there was a discernible plurality in the 2000s. Date range is characteristically different from the other categories, given the arbitrary designation of decades. Noting that a citation was from the 1990s provides an approximate sense of how much time has passed between the publication of a cited source and its citing work. The date range alone does not necessarily provide any information about the nature of the scholarly arguments expressed in the work, though it could serve as an indicator, with further analysis.

It is worth noting that citations from the same decade as the citing works, the 2010s, were less prevalent than citations from the 2000s, the 1990s, and the 1980s. In other words, while historians were most likely to cite scholarship from between 5 and 10 years prior, they were also more likely to cite scholarship from 20 or 30 years prior than from 1-5 years prior. As mentioned above, this finding suggests an interest in currency, but one that is commensurate with the continuing dominance of monographs, which are likely to retain currency for longer periods than other formats and which may not be reviewed until several years after publication. This qualified version of currency makes sense in the context of earlier studies that have found consistently that book reviews have served an important role in historians' discovery of new scholarship. ${ }^{38}$

The prevalence of English language sources is also noteworthy, for a citation analysis stemming from a flagship journal that includes all historical subfields. While there is a possibility that the results reflect a tendency of historians in the United States to consult and cite English language sources, this study does not present sufficient evidence to support such a 
conclusion beyond the realm of secondary literature. Similar to the consideration of format characteristics above, it is likely that inclusion of archival, government, and manuscript materials would have yielded a greater diversity of languages than was found in the present study. As the present analysis allows reflection upon general patterns in secondary literature, it does prompt the question of whether the sources cited reflect a widespread tendency of scholars everywhere to publish in English. ${ }^{39}$ Lowe also reflected on the dominance of English in a study that did not exclude unpublished material and, for a possible explanation, quoted a 1977 study by Buchanan and Herubel, which asserted that flagship journals may represent "hegemonic attempts at uniformity and disciplinary activity." 40 Lowe went on to ask the compelling question, "Do mainstream, less-specialized journals lose out on diversity when they become the 'spokesman' for a profession?" ${ }^{41}$ Further mining of the citation data for the present study may contribute to a clearer understanding of this and related questions.

With awareness that articles represented in this study were most likely to cite monographs, recently published works, and English language materials, we can turn our attention to the representation and discoverability of these works across the selected search platforms.

\section{Part 2: Which Search Platforms Represent This Body of Literature?}

The primary question posed by this study asks where scholarly literature in history is discoverable, to better understand and optimize the coexistence of web scale discovery services alongside conventional disciplinary databases. Accordingly, one way of approaching the results is to ask which platform or platforms came closest to approximating the sample of cited references, through representation of formats, languages, and publication date ranges.

Taking all three of those criteria into consideration, it is clear from the results that Google Scholar, ArticlesPlus, and WorldCat each came close to mirroring the sample, while both JSTOR and AHL/HA did not. Considering quantity only, Google Scholar emerged as the platform through which the largest portion of the sample could be identified, with ArticlesPlus a close second. Following Google Scholar and ArticlesPlus, WorldCat found the next highest quantity of citations, offering what are arguably the most comprehensive and highest quality bibliographic descriptions, compared to any of the other platforms. While both WorldCat and ArticlesPlus included 10 of the 15 formats represented in the sample, WorldCat was noticeably weaker in representing some formats, such as newspaper articles. This is not surprising, given WorldCat's longstanding role as a catalog, as opposed to periodical index.

Through further analysis, a very noticeable divide is discernible among the three tools that found the most citations - Google Scholar, ArticlesPlus, and WorldCat-and the three that found the fewest: JSTOR and AHL/HA. On average, Google Scholar, ArticlesPlus, and WorldCat found 308 of the 400 citations, or about 77 percent. By contrast, the average number found by JSTOR and AHL/HA was 75, or about 19 percent. On the surface, this finding suggests that historians are citing sources across a wide range of disciplines, formats, and languages and that the literature of the field is most comprehensively captured by a discovery tool that can also span such a wide range. Remarks made by Stieg in her 1981 study have enduring resonance, as she described "an important fact about history [...] history is really only an umbrella term covering a wide variety of specializations that have little in common with each other but their method." ${ }^{42}$ Historians necessarily consult the literature of the subfield in which they are working, which may be characterized by topics or emphases ranging from social and cultural to medical, scientific, or environmental. In addition, historians rely on bodies of theory and 
criticism that emerge from other disciplinary traditions, such as area studies, gender studies, literary analysis, and political science. In other words, historical literature is not singularly defined and is unlikely to be well encapsulated in any search tool that is limited by discipline.

This finding also reinforces one of the questions that is central to this study, namely, how to discern the enduring value of conventional disciplinary databases and/or A\&I tools. While results from a single citation analysis may not be definitive, those presented here do not suggest clear or unique value to the discovery of historical literature by the companion databases that are the most well known among library professionals: AHL/HA. Consequently, the present study suggests that there is not currently a subject-specific database that can claim to serve the discipline of history well and especially not better than multidisciplinary tools that operate at scale.

The multidisciplinary nature of historical literature cannot explain the gap between the top performing platforms and JSTOR, which is also multidisciplinary in nature, but represented only 16.5 percent of the sample. While JSTOR continues to observe a 3- to 5-year "moving wall" for much of its journal content, this should not necessarily impact the present study, which found that historians were most likely to cite sources that were at least a few years old. This study does not suggest that JSTOR is not a useful tool for historians to consult, especially considering its enduring popularity. Historian Lara Putnam named only one library database in her recent article on the impact of digital search tools on historical research and production, and it was JSTOR, typically grouped with and listed after tools like Google, Google Books, and Wikipedia. Discussing library databases generally, Putnam referred to "JSTOR and kin" to elucidate. ${ }^{43}$ The present study does suggest that historians are consulting and citing sources from a much wider sphere than what has been captured in the JSTOR archive and that there are platforms, such as ArticlesPlus, that tap into that sphere to a far greater extent.

It is worth reiterating that neither JSTOR nor AHL/HA provided particularly strong coverage of journal articles, though both tools have traditionally specialized in providing access to journal literature. One explanation for this finding may be that it indicates limitations of the citation analysis method. However, the citations gathered for this study were tailored to represent secondary literature, specifically to ensure that JSTOR and AHL/HA would not be at an unfair disadvantage. A more complete explanation may emerge from further analysis of the citation data. For example, Jones, Chapman, and Woods were able to glean a set of commonly used, if not conclusively "core," journals for the field of English history in their 1972 study. ${ }^{44}$ It may be the case that a set of journals approaching core status would not emerge from this study, given the scope of the AHR. Further analysis of journal titles cited may help explain the weak performances of both AHL/HA and JSTOR.

Despite the narrowness of AHL/HA and the multidisciplinary nature of JSTOR, AHL/ HA actually outperformed JSTOR in this study, finding 21 percent of the sample. However, compared to the other platforms, AHL/HA emerges as a tool whose utility lies in indexing only a very narrow subset of secondary literature in history. Consequently, library professionals likely do a disservice to students and faculty if we perpetuate the notions that all disciplines have their primary indexes; that, in comparison to web scale services, these indexes are most appropriate for advanced research needs; and that, for history, AHL and HA are standard bearers. For example, Kirkwood and Kirkwood conveyed such a perspective in their admittedly "nonscientific analysis," which began with unbridled praise for Historical Abstracts, declaring that "no other history research tool matches its scholarly standards or comprehensive 
coverage." 45 Thomas Mann argued as recently as 2015 that "the silo databases for individual disciplinary areas are there for a reason," namely, to provide indexing coverage to the "most important journals within their subjects, undiluted by thousands of tangential periodicals." 46 Without further analysis, it is impossible to say conclusively whether the 57 percent of journal articles that were not indexed by AHL/HA in the present study can be considered "tangential," but such a claim would strike the author as unlikely.

It is important to reiterate that this study did not include qualitative analysis and does not offer evidence to equate the presence of more citations with better usability. While citations were identifiable in Google Scholar, as such, they were not necessarily attached to bibliographic records or links to full text, features that generally enhance the discovery experience. The relative merits and drawbacks of Google Scholar have received considerable scrutiny in the literature. ${ }^{47}$ The evidence presented here is consequential for Google Scholar, insofar as it suggests that its scope is not necessarily as weak for nonscience fields as has been suggested elsewhere. ${ }^{48}$

While ArticlesPlus did provide records for all citations found, the quality and completeness of records varied, and inconsistencies and errors in indexing were observed. This can be explained, at least in part, by Summon's method of creating hybrid records that reflect metadata and full text from multiple sources. In theory, items indexed in Summon should be represented by these single, hybrid records, though matching is not consistently successful in practice. This observation aligns with a widely cited critique of web scale discovery services, to the effect that they are "only as effective as the quality and completeness of the metadata they ingest, process and index" and could benefit from increased standardization. ${ }^{49}$ However, in addition to its vast scope of coverage, ArticlesPlus is configured with robust delivery options, providing users with reliable paths to locate materials in library holdings - or to request assistance - via an institutionally branded link resolver. By contrast, Google Scholar's many textual citations may be easily construed as dead ends if researchers lack experience pursuing results presented in such brevity. As with any locally configured web scale tool, the delivery environment of ArticlesPlus, designed to work in tandem with its discovery features, reflects the commitment and continuing investments of the affiliated institution, more so than features inherent to Summon.

An unexpected finding was that WorldCat contained records for 18 journal articles (20\%), out of the 90 included in the sample. By comparison, JSTOR contained records for 34 journal articles (38\%), while AHL/HA contained records for 39 (43\%). This finding almost certainly represents some libraries' local practice of cataloging journal articles according to specified circumstances. It does not translate to a recommendation to use WorldCat for locating journal articles, but it does indicate that WorldCat is not as far behind JSTOR and AHL/HA in describing them as the author would have guessed. While WorldCat performed relatively well for many formats, languages, and date ranges, it is worth noting that the FirstSearch platform does not provide features that define web scale tools or that are consistent with user expectations, as outlined above. This circumstance may be remedied by libraries' adoption of the WorldCat Discovery service, untested in the present study.

The present study does not suggest that AHL/HA are not useful tools for historians and students seeking secondary sources, even if they do not merit recognition as the biggest or best tools for finding historical literature. These tools provide access to a set of prominent history journals, though unrepresentative of the range of sources that historians consult. Previous 
qualitative studies that have found AHL/HA to be useful are not necessarily negated by the very quantitative approach taken here. If the so-called "silo databases" do continue to bring value, it is likely related to the ability to search a relatively smaller and more specialized haystack than a web scale tool can provide.

\section{Part 3: Limitations}

There are several limitations to the present study. First, the analyzed citations come from articles in a single journal within a specified six-year time frame. While the results align with findings from other studies using varying methodologies and covering varying time periods, it may still be the case that different patterns would emerge from citation analysis that included citations gathered from other formats, such as books, as well as from articles in other, more specialized, historical journals.

There are well documented limitations to citation analysis as a methodology. Jones, Chapman, and Woods quoted an enduring criticism of the method, to the effect that "an author need not cite what he reads nor read what he cites." 50 Stieg also noted that citation studies "can only analyze what is actually cited," which is unlikely to be everything that was used, and mentions that citation studies "cannot show relative importance among sources." 51 While these critiques suggest that what gets cited cannot give us a full picture, they should not inhibit attempts to discern and interpret meaningful patterns among cited works.

The search method used in this study entailed known item searches, conducted by a professional librarian, often taking advantage of advanced, fielded search options. Searching of this nature, done to form a confident basis for a quantitative assessment, is very different from the exploratory or topical searching that a researcher of any experience level might engage in. The ability to find a known item with a complete citation can only partially capture its discoverability. Scholarly literature must also be discoverable through topical searching, untested by this study. However, the present study does bear consequence for a clearer understanding of what is potentially discoverable wherein it adds to our knowledge of the types and volumes of sources we can expect to find in specific search platforms.

Finally, the study only considers the discipline of history, which may be more interdisciplinary in nature than other fields. While the present study cannot describe the value that A\&I tools may bring to the research experience across all disciplines, it does contribute to a clearer understanding that all A\&I tools are not equally valuable and that their relationship to web scale discovery tools cannot be characterized categorically.

\section{Conclusion}

The findings presented here point to several insights into historical literature and its discoverability. While English language monographs, published relatively recently, continue to stand out among work cited by historians, the full scope of this work is better represented by library discovery tools that incorporate wide ranges of formats, subject areas, date ranges, and languages than by the relatively narrower tools that researchers and library professionals alike have tended to associate with historical research. Because none of the search platforms that were tested found a sizable number of citations that were not found in any of the other tools, it is not possible to draw firm conclusions about discernible strengths for specified formats, languages, or date ranges. With the finding that book chapters and newspaper articles were most likely to be either uniquely represented or unrepresented across search platforms, the 
study suggests that discoverability for these formats in particular may be weaker than for other formats.

The evidence presented here should prompt more skepticism of, or potentially help to dismantle, the assumption that subject databases are always best for advanced uses, with web scale tools conceived as "supplementary" and better suited to the domain of initial or novice queries. While the experience of searching a smaller, more targeted index will likely continue to hold appeal and serve a purpose, our professional understanding of the roles of A\&I tools needs to be qualified and merits greater evaluative attention. Some disciplines will likely continue to be well served by a strong A\&I service that represents the vocabulary and the literature of the field; as the present study suggests, such is not the case for all fields.

Further, the awareness that disciplinary databases are not necessarily the best tools for advanced uses cannot necessarily be accompanied by an assumption that the opposite is true. The legacy configurations of many A\&I interfaces will not be met as favorably as web scale discovery tools by users accustomed to the single search box experience. Libraries will do well to conduct further research into the enduring value of A\&I tools and design solutions to bring their assets into the web scale discovery environment, characterized by robust options for discovery, delivery, and access to discipline-specific search mechanisms, when and where appropriate.

\section{Acknowledgements}

The author is especially grateful to Ken Varnum and Lettie Conrad for their comments on earlier versions of this paper and to Beau Case for support and encouragement during the early phases of this project. Josh Ringuette and Alexandra Andre provided indispensable assistance with data collection. The staff of the University of Michigan Library's Research Data Services unit has enabled the preservation and sharing of this project's relevant data. Many thanks to all.

\section{Notes}

1. Andrew D. Asher, Lynda M. Duke, and Suzanne Wilson, "Paths of Discovery: Comparing the Search Effectiveness of EBSCO Discovery Service, Summon, Google Scholar, and Conventional Library Resources," College E Research Libraries 74, no. 5 (Sept. 2013): 464, doi:10.5860/crl-374; Mary M. Somerville and Lettie Y. Conrad, "Collaborative Improvements in the Discovery of Scholarly Content: Accomplishments, Aspirations, and Opportunities: A SAGE White Paper," available online at https:/studysites.sagepub.com/repository/binaries/ pdf/improvementsindiscoverability.pdf [accessed 6 December 2017]; Courtney Lundrigan, Kevin Manuel, and May Yan, "Pretty Rad': Explorations in User Satisfaction with a Discovery Layer at Ryerson University," College \& Research Libraries 76, no.1 (Jan. 2015): 43, doi:10.5860/crl.76.1.43; Marshall Breeding, "The Future of Library Resource Discovery," Information Standards Quarterly 27, no. 1 (Spring 2015): 24-30.

2. Jason Vaughan, "Web Scale Discovery What and Why," Library Technology Reports 47, no. 1 (2011): 5-11.

3. Beth Thomsett-Scott and Patricia E. Reese, "Academic Libraries and Discovery Tools: A Survey of the Literature," College \& Undergraduate Libraries 19, no. 2/4 (Apr. 2012): 128, doi:10.1080/10691316.2012.697009; Nancy Fawley and Nikki Krysak, "Information Literacy Opportunities within the Discovery Tool Environment," College \& Undergraduate Libraries 19, no. 2/4 (Apr. 2012): 213, doi:10.1080/10691316.2012.693439; Stefanie Buck and Margaret Mellinger, “The Impact of Serial Solutions' Summon ${ }^{\mathrm{TM}}$ on Information Literacy Instruction: Librarian Perceptions," Internet Reference Services Quarterly 16, no. 4 (July 2011): 165, doi:10.1080/10875301.2011.621864.

4. The vast literature on discovery has been well analyzed in several review articles, as well as compiled into edited volumes. A selection of these include: Thomsett-Scott and Reese, "Academic Libraries and Discovery Tools"; Nadine P. Ellero, "Integration or Disintegration: Where Is Discovery Headed?" Journal of Library Metadata 13, no. 4 (Oct. 2013): 311-29, doi:10.1080/19386389.2013.831277; Planning and Implementing Resource Discovery Tools in Academic Libraries, eds. Diane Dallis and Mary Pagliero Popp (Hershey, PA: Information Science Reference, 2012). 
5. Asher, Duke, and Wilson, "Paths of Discovery," 464-88; Sarah P.C. Dahlen and Kathlene Hansen, "Preference vs. Authority: A Comparison of Student Searching in a Subject-Specific Indexing and Abstracting Database and a Customized Discovery Layer," College E Research Libraries 78, no. 7 (Nov. 2017): 878-97, doi:10.5860/crl.78.7.878; Jeffrey Daniels, Laura Robinson, and Susan Wishnetsky, "Results of Web-Scale Discovery: Data, Discussions, and Decisions," Serials Librarian 64, no. 1/4 (Jan. 2013): 81-87, doi:10.1080/0361526X.2013.761056; Suqing Liu, Sansan Liao, and Jing Guo, "Surviving in the Digital Age by Utilizing Libraries' Distinctive Advantages," Electronic Library 27, no. 2 (Apr. 10, 2009): 298-307, doi:10.1108/02640470910947647.

6. Nadine P. Ellero, "An Unexpected Discovery: One Library's Experience with Web-Scale Discovery Service (WSDS) Evaluation and Assessment," Journal of Library Administration 53, no. 5/6 (July 2013): 323-43, doi:10 .1080/01930826.2013.876824; Amy I. Kornblau, Jane Strudwick, and William Miller, "How Web-Scale Discovery Changes the Conversation: The Questions Librarians Should Ask Themselves," College \& Undergraduate Libraries 19, no. 2/4 (Apr. 2012): 144-62, doi:10.1080/10691316.2012.693443; Thomsett-Scott and Reese, "Academic Libraries and Discovery Tools"; Vaughan, "Web Scale Discovery What and Why."

7. Ellero, "An Unexpected Discovery," 325; Kenneth J. Varnum, "A Brief History of the Open Discovery Initiative," Learned Publishing 30, no.1 (Jan. 2017): 45-48, doi:10.1002/leap.1078; Rachel Kessler et al., "Optimizing the Discovery Experience through Dialogue: A Community Approach," Insights 30, no. 2 (July 2017): 32, doi:10.1629/ uksg.367.

8. Varnum, "A Brief History of the Open Discovery Initiative"; Jenny Walker, "The NISO Open Discovery Initiative: Promoting Transparency in Discovery," Insights 28, no. 1 (Mar. 2015): 85, doi:10.1629/uksg.186; Nettie Lagace, "NISO Releases Recommendations from the Open Discovery Initiative: Promoting Transparency in Discovery Working Group," Serials Review 40, no. 4 (Oct. 2014): 287-88, doi:10.1080/00987913.2014.978244; Michael Kelley, "Coming into Focus," Library Journal 137, no. 17 (Oct. 15, 2012): 34.

9. Ellero, "An Unexpected Discovery," 326; Kessler et al., "Optimizing the Discovery Experience through Dialogue"; Marshall Breeding, "Looking Forward to the Next Generation of Discovery Services," Computers in Libraries 32, no. 2 (Mar. 2012): 29; Andrew J. Welch, "Implementing Library Discovery: A Balancing Act," in Planning and Implementing Resource Discovery Tools in Academic Libraries, eds. Diane Dallis and Mary Pagliero Popp (Hershey, PA: Information Science Reference, 2012), 325.

10. Asher, Duke, and Wilson, "Paths of Discovery," 476; Buck and Mellinger, "Impact of Serial Solutions' Summon ${ }^{\mathrm{TM}}, " 170$.

11. Ellero, "An Unexpected Discovery," 326; Buck and Mellinger, "Impact of Serial Solutions' Summon ${ }^{\mathrm{TM}}$ on Information Literacy Instruction," 165.

12. Thomsett-Scott and Reese, "Academic Libraries and Discovery Tools," 128; Fawley and Krysak, "Information Literacy Opportunities within the Discovery Tool Environment," 213; Buck and Mellinger, "The Impact of Serial Solutions' Summon ${ }^{\mathrm{TM}}$ on Information Literacy Instruction," 165.

13. Catherine Cardwell, Vera Lux, and Robert J. Snyder, "Beyond Simple, Easy, and Fast: Reflections on Teaching Summon," College and Research Libraries News 73, no. 6 (2012): 344-47, available online at https://crln.acrl.org/ index.php/crlnews/article/view/8778/9344 [accessed 18 September 2017 ]; Asher, Duke, and Wilson, "Paths of Discovery," 474.

14. Asher, Duke, and Wilson, "Paths of Discovery."

15. Dahlen and Hanson, "Preference vs. Authority," 884-86.

16. Ibid., $883,887$.

17. Ibid., 892.

18. Carol Tenopir, "Evaluation of Database Coverage: A Comparison of Two Methodologies," Online Review 6, no. 5 (1982): 423-41; Thomas E. Nisonger, "Use of the Checklist Method for Content Evaluation of Full-Text Databases: An Investigation of Two Databases Based on Citations from Two Journals," Library Resources $\mathcal{E}$ Technical Services 52, no. 1 (Jan. 2008): 4-17.

19. Nisonger, "Use of the Checklist Method," 4.

20. Kee DeBoer, "Abstracting and Indexing Services for Recent U.S. History," RQ 28, no. 4 (1989): 537-45.

21. Jennalyn W. Tellman, "A Comparison of the Usefulness of IBZ and FRANCIS for Historical Research," Reference \& User Services Quarterly 41, no. 1 (Fall 2001): 56-66; Hal P. Kirkwood and Monica C. Kirkwood, "Historical Research: Historical Abstracts with Full Text or Google Scholar," Online 35, no. 4 (Aug. 2011): 28-32.

22. Clyve Jones, Michael Chapman, and Pamela Carr Woods, "The Characteristics of the Literature Used by Historians," Journal of Librarianship 4, no. 3 (July 1972): 142, doi:10.1177/096100067200400301; Margaret F. Stieg, "The Information Needs of Historians," College $\mathcal{E}$ Research Libraries 42, no. 6 (1981): 551, 554, doi:10.5860/crl_42_06_549.

23. Margaret Stieg Dalton and Laurie Charnigo, "Historians and Their Information Sources," College E Research Libraries 65, no. 5 (2004): 405, doi:10.5860/crl.65.5.400. 
24. M. Sara Lowe, "Reference Analysis of the American Historical Review," Collection Building 22, no. 1 (2003): 15, doi:10.1108/01604950310457168.

25. Kirkwood and Kirkwood, "Historical Research," 32.

26. Ibid., 32.

27. American Historical Association, "About the American Historical Review," available online at https:/ www.historians.org/publications-and-directories/american-historical-review/about-the-american-historicalreview [accessed 18 September 2017].

28. Alexa L. Pearce, Discovering History: An Analysis of Secondary Literature Cited in the American Historical Review, 2010-2015 (Oct. 2, 2017), distributed by Deep Blue Data, doi:10.7302/Z2QR4V9S.

29. DeBoer, "Abstracting and Indexing Services for Recent U.S. History," 539.

30. Lara Putnam, "The Transnational and the Text-Searchable: Digitized Sources and the Shadows They Cast," American Historical Review 121, no. 2 (Apr. 2016): 378, doi:10.1093/ahr/121.2.377; Dalton and Charnigo, "Historians and Their Information Sources," 411.

31. At the time of submission, the U-M Library is preparing to launch a consolidated search interface that will allow users to search simultaneously across its catalog as well as all content from ArticlesPlus, along with database and journal holdings.

32. The full list of citations found in only one search platform is included in the published data for this study. See Pearce, Discovering History.

33. The full list of citations that were not found in any of the search platforms is included in the published data for this study. See Pearce, Discovering History.

34. The full list of citations found in all search platforms is included in the published data for this study. See Pearce, Discovering History.

35. Dalton and Charnigo, "Historians and Their Information Sources"; Lowe, "Reference Analysis of the American Historical Review," 15-16.

36. American Historical Association, "Guidelines for the Professional Evaluation of Digital Scholarship by Historians," available online at https://www.historians.org/teaching-and-learning/digital-history-resources/ evaluation-of-digital-scholarship-in-history/guidelines-for-the-professional-evaluation-of-digital-scholarshipby-historians [accessed 26 September 2017].

37. Dalton and Charnigo, "Historians and Their Information Sources," 406.

38. Stieg, "The Information Needs of Historians," 554; Dalton and Charnigo, "Historians and Their Information Sources," 408.

39. Mary Jane Curry and Theresa Lillis, "The Dominance of English in Global Scholarly Publishing," International Higher Education, no. 46 (Winter 2007), doi:10.6017/ihe.2007.46.7948.

40. Lowe, "Reference Analysis of the American Historical Review," 16.

41. Ibid., 16.

42. Stieg, "The Information Needs of Historians," 550.

43. Putnam, "The Transnational and the Text-Searchable," 378, 383.

44. Jones, Chapman, and Woods, "The Characteristics of the Literature Used by Historians," 145.

45. Kirkwood and Kirkwood, "Historical Research," 29.

46. Thomas Mann, The Oxford Guide to Library Research (New York, NY: Oxford University Press, 2015), 79.

47. Hannah Rozear, "Where 'Google Scholar' Stands on Art: An Evaluation of Content Coverage in Online Databases," Art Libraries Journal 34, no. 2 (Apr. 2009): 21-25; Julie Arendt, "Imperfect Tools: Google Scholar vs. Traditional Commercial Library Databases," Against the Grain 20, no. 2 (2008): 26, 28, 30; Xiaotian Chen and Kevin O’Kelly, "Cross-Examining Google Scholar," Reference \& User Services Quarterly 52, no. 4 (2013): 279-82.

48. Rozear, "Where 'Google Scholar' Stands on Art"; Kirkwood and Kirkwood, "Historical Research."

49. Ellero, "Integration or Disintegration," 316.

50. Jones, Chapman, and Woods, "The Characteristics of the Literature Used by Historians," 139.

51. Stieg, "The Information Needs of Historians," 549. 